\title{
HUBUNGAN SHIFT KERJA DENGAN KELELAHAN KERJA PADA PERAWAT DI INSTALASI RAWAT INAP DI RUMAH SAKIT HERNA MEDAN TAHUN 2018
}

\author{
Nur aini \\ Institut Kesehatan Helvetia Medan \\ Email: nuraini@helvetia.ac.id
}

\begin{abstract}
The hospital is a health care facility operates 24 hours. The Responsibilities and workload of nurses to note with the division of labor, such as morning shift, noon shift, and night shift. The division of this shift can give negative impact which one is fatigue. Relationships shift work with fatigue on nurses inpatient in Herna hospital. The research design is descriptive analytic with a cross sectional approach. The population in this study were all the nurses the inpatientusing a simple random sampling technique as many as 57nurses. Data analysis used statistical test using chi-square. there is a level of fatigue in the category of less tired as many as 12 people (63.2\%), tired as many as 7 people (36.8\%). And in the noon shift nurse there was a level of fatigue in the category of tiredness as many as 12 people (63.2\%), tired as much as 6 people (31.6\%) and very tired as much as 1 person (5.3\%). At night shift nurses there is a level of fatigue in the category of tiredness as many as 3 people (15.8\%), tired as many as 14 people (73.7\%) and very tired as much as 2 people (10.5\%). From the results in this research obtained a significant value of $p=0.016$ or $p<0.05$. There is a work shift relationship with work fatigue in nurses in inpatient installations at Imelda General Hospital Medan Indonesian Workers.
\end{abstract}

Keywords: Work shift, Fatigue, Nurse, Health care, Moorning shift, Noon shift

\section{PENDAHULUAN}

Shift kerja diartikan berada pada lokasi kerja yang sama (shift kerja kontiniu) atau pada waktu yang berlainan (shift kerja rotasi). Shift kerja berbeda dengan hari kerja biasa, dimana pada hari kerja biasa, pekerjaan dilakukan secara teratur pada waktu yang telah ditentukan sebelumnya, sedangkan shift kerja dapat dilakukan lebih dari satu kali untuk memenuhi jadwal 24 jam/hari. Alasan lain dari shift kerja adalah kebutuhan sosial akan pelayanan. Di Inggris dan Eropa biasanya diterapkan dari pukul
06.00 sampai 14.00 (shift pagi), 14.00 sampai 20.00 (shift sore) dan 20.00 sampai 06.00 (shift malam) - atau satu jam (bisa 2 jam) lebih dulu untuk tiap shift (Nurmianto, 2018).

Rumah sakit yang memberikan pelayanan rawat inap mengharuskan adanya pengaturan shift kerja agar pelayanan kesehatan terus diberikan kepada seluruh pasiennya. Didalam Undang - Undang No.13 tahun 2003 tentang ketenagakerjaan, setiap pengusaha atau pelayanan kesehatan diwajibkan untuk melaksanakan 
ketentuan jam kerja. Karena ada ketentuan tersebut dan proses kerja tidak bisa berhenti, maka diaturlah pembagian waktu kerja bagi setiap karyawan atau pegawai dengan shift kerja. Periode kerja dibagi menjadi 3 yaitu periode pagi sampai sore, periode sore sampai malam dan ada yang bekerja pada periode malam sampai pagi (Kemenkes, 2013).

Jumlah jam kerja yang efisien untuk seminggu adalah antara 40 - 48 jam yang terbagi dalam 5 atau 6 hari kerja. Maksimum waktu kerja tambahan yang masih efisien adalah 30 menit. Apabila jam kerja melebihi dari ketentuan tersebut akan ditemukan hal seperti; penurunan kecepatan kerja, gangguan kesehatan, angka absensi karena sakit meningkat, yang kesemuanya akan bermuara pada rendahnya produktivitas kerja (Tarwaka, 2004) Pergeseran waktu kerja dari pagi, siang dan malam hari dapat mempengaruhi terjadinya peningkatan kecelakaan akibat kerja (Sucipto, 2014)

Kelelahan merupakan suatu mekanisme perlindungan tubuh agar tubuh terhindar dari kerusakan lebih lanjut sehingga terjadi pemulihan setelah istirahat. Kelelahan diatur secara sentral oleh otak. Pada susunan syaraf pusat terdapat sistem aktivasi (bersifat simpatis) dan inhibisi (bersifat para simpatis). Kelelahan diklasifikasikan dalam dua jenis yaitu kelelahan otot dan kelelahan umum. Kelelahan subjektif biasanya diakhir jam kerja, apabila beban kerja melebihi rata - rata $30-40 \%$ dari tenaga aerobik maksimal (Tarwaka, 2004).

Kelelahan kerja menurunkan kinerja dan menambah tingkat kesalahan kerja dan terjadinya kecelakaan kerja dalam industri. Pembebanan otot secara statis (static muscular loading) jika dipertahankan dalam waktu yang cukup lama akan mengakibatkan RSI (Repetition Strain Injuries), yaitu nyeri otot, tulang, tendon, dan lain-lain yang diakibatkan oleh jenis pekerjaan yang bersifat berulang (repetitive). Karakteristik kelelahan kerja akan meningkat dengan semakin lamanya pekerjaan yang dilakukan, sedangkan menurunnya rasa lelah (recovery) adalah didapat dengan memberikan istirahat yang cukup (Nurmianto, 2018). Kelelahan akibat tidak ergonomisnya kondisi sarana, prasarana dan lingkungan kerja merupakan faktor dominan bagi menurun atau rendahnya produktivitas kerja tenaga kerja.suasana kerja yang tidak ditunjang oleh kondisi lingkungan kerja yang sehat, nyaman, aman, dan 
selamat akan memicu timbulnya kelelahan pada tenaga kerja (Budiono, 2003).

Rumah sakit sebagai sarana upaya perbaikan kesehatan yang melaksanakan pelayanan kesehatan sekaligus sebagai lembaga pendidikan tenaga kesehatan dan penelitian ternyata memiliki dampak positif dan negative terhadap lingkungan sekitarnya. Fasilitas rawat inap yang banyak dimanfaatkan penduduk Indonesia adalah rumah sakit pemerintah (38\%), rumah sakit swasta $(35 \%)$ dan puskesmas (11\%) (Adisasmito, 2007). Perawat adalah seseorang yang telah menyelesaikan pendidikan keperawatan yang memenuhi syarat, serta berwenang di negeri bersangkutan untuk memberikan pelayanan keperawatan yang bertanggung jawab untuk meningkatkan kesehatan, pencegahan penyakit, dan pelayanan penderita sakit (Budiono, 2015).

Seseorang dapat dikatakan sebagai perawat dan mempunyai tanggung jawab sebagai perawat manakala yang bersangkutan dapat membuktikan bahwa dirinya telah menyelesaikan pendidikan perawat baik di luar maupun di dalam negeri yang biasanya dibuktikan dengan ijazah atau surat tanda tamat belajar (Kemenkes, 2014).
Pelayanan keperawatan yang berkualitas akan sulit dilaksanakan jika suplai tenaga kesehatan yang tidak memadai, serta sistem kesehatan yang tidak diperhatikan. Selain itu, kita pun tidak pungkiri bahwa ditengah besarnya tuntutan terhadap perawat agar memberikan pelayanan terbaik kepada masyarakat serta beratnya risiko yang dihadapi (Febrian, 2015).

Permasalahan pokok yang berhubungan dengan shift kerja adalah terkadang pekerja tidur saat kegiatan sosial berlangsung. Hal ini menyebabkan pekerja sulit memberikan waktunya pada keluarga, berkumpul dengan teman atau berinteraksi dengan masyarkat untuk mendapatkan nilai sosial yang besar (Nurmianto, 2018).

Suatu sistem syaraf manusia biasanya memiliki daya tolak yang luar biasa terhadap perubahan yang tiba - tiba. Jadi, penjadwalan kerja seharusnya diatur sehingga tidak mengganggu sistem syaraf tersebut secara berlebihan. Biasanya hal ini dilakukan dengan memberikan perubahan bersifat sementara dan berikutnya pekerja dikembalikan pada kondisi normalnya. Misalnya, seseorang perkerja hanya menjalani satu shift malam dalam satu minggunya. 
Rumah Sakit Herna Medan merupakan RS kelas B Non pendidikan. Berdasarkan data profil rumah sakit tahun 2016 yang diperoleh, pada RS Herna khususnya bagian rawat inap memiliki ruangan rawat inap terdiri atas memiliki Kamar VVIP, VIP, Kelas I, Kelas II dan kelas II dengan total jumlah tenaga perawat 130 orang. Jumlah pasien rawat inap yang dirawat pada tahun 2016 sebanyak 14.622 orang, sedangkan pada tahun 2017 sebanyak 14.443 orang (Profil RS Herna, 2016).

Berdasarkan survey awal yang telah dilakukan, di RS Herna Medan memberlakukan sistem shift kerja dengan 3 shift, yaitu shift pagi, shift sore dan shift malam. Sistem rotasi yang digunakan pada RS Herna Medan adalah model sistem rotasi 2-2-2. Shift pagi dimulai pada pukul $08.00-16.00 \mathrm{WIB}$, Shift sore dimulai pada pukul $16.00-23.00$ WIB dan Shift malam dimulai pukul 23.00 08.00 WIB. Pada shift pagi, jumlah perawat yang berjaga sebanyak 4 orang perawat. Pada shift sore, jumlah perawat yang berjaga sebanyak 3 orang perawat tanpa kepala ruangan. Pada saat shift malam, jumlah perawat yang berjaga sebanyak 2 - 3 orang.

Berdasarkan wawancara singkat yang dilakukan terhadap 2 kepala ruangan dan 4 orang perawat dari masing - masing ruangan tentang tugas pershift kerja perawat di dapatkan informasi bahwa perawat pada shift pagi banyak tugas pekerjaan yaitu mendampingi dokter saat memeriksa keadaan pasien, mengganti sprei pasien, melengkapi data pasien, mengantar pasien yang akan melakukan pemeriksaan laboratorium, fisiologi, radiologi dan mengantarkan pasien yang akan di operasi, merangkum keluhan - keluhan pasien dan keluarga pasien, serta mengobservasi pasien secara berkala sehingga job desk dari perawat yang berlebihan dapat menyebabkan kelelahan.

Pada shift sore tugas perawat melanjutkan pekerjaan perawat shift pagi yaitu mengobservasi kembali pasien, mengurus berkas administrasi yang belum siap, mengganti infus pasien, Menunggu dokter yang belum datang, memberi obat pasien dan mengantar pasien yang akan melakukan pemeriksaan laboratorium, fisiologi, radiologi dan mengantarkan pasien yang akan di operasi. Pada shift sore perawat juga banyak mengeluh lelah dan pusing menghadapi keluhan pasien yang selalu mamanggil dan terkadang marah karena dokter lama datang, banyaknya tuntutan dari keluarga pasien, jumlah tenaga 
perawat lebih sedikit dan Jam kerja mereka dari jam 16.00 wib sampai 23.00 wib sehingga menyebabkan mereka mengantuk dan lelah.

Pada shift malam tugas perawat yaitu mengecek keadaan pasien, memberi obat, membereskan dokumen administrasi, dan melihat persediaan keperluan di ruangan yang telah habis seperti infus, obat-obatan. Pada shift malam perawat juga mengeluh mengantuk, pusing dan lelah karena perawat harus bekerja pada malam hari dimana waktu tersebut seharusnya digunakan untuk istirahat. Berdasarkan uraian permasalahan di atas, maka ingin meneliti lebih lanjut mengenai hubungan shift kerja dengan kelelahan kerja pada perawat rawat inap di RS Herna Medan. Tujuan penelitian ini adalah untuk mengetahui hubungan shift kerja dengan kelelahan kerja pada perawat instalasi rawat inap di RS Herna Tahun 2018.

\section{METODE PENELITIAN}

Jenis penelitian ini adalah penelitian yang bersifat deskriptif analitik dengan pendekatan cross sectional. Penelitian cross sectional adalah dimana data yang menyangkut variabel bebas atau risiko dan variabel terikat atau variabel akibat, akan dikumpulkan dalam waktu yang bersama (Notoatmodjo, 2005)

Populasi adalah seluruh data yang menjadi perhatian kita dalam suatu ruang lingkup dan waktu yang kita tentukan (Margono, 2013). Populasi penelitian adalah seluruh perawar rawat inap yang bekerja di RS Herna Medan yaitu sebanyak 130 perawat rawat inap. Sampel Penentuan jumlah sampel dengan menggunakan menggunakan rumus slovin dengan teknik simple random sampling sebanyak 57 perawat rawat inap.

Analisis data pada penelitian ini menggunakan analisis univariat dan analisis bivariat untuk mengetahui hubungan (kolerasi) antara variabel bebas (independent variabel) dengan variabel terikat (dependent variabel) menggunakan chi square.

\section{HASIL PENELITIAN}

\section{Karakteristik Responden:}

Berdasarkan hasil pengumpulan data tentang karakteristik dilihat pada tabel 1 dapat dilihat bahwa jumlah mayoritas perawat berumur $<25$ tahun yaitu sebanyak 33 orang (57,9\%). Mayoritas perawat yang berjenis kelamin laki - laki sebanyak 17 orang $(29,8 \%)$. Masa kerja $<5$ tahun sebanyak 48 orang $(84,2 \%)$. Perawat dengan status 
perkawinan yang sudah menikah

sebanyak 22 orang $(38,6 \%)$.

Tabel 1 Distribusi Frekuensi Karakteristik Perawat Rawat Inap

\begin{tabular}{|c|c|c|}
\hline Karakteristik & Frekuensi (f) & Persentase (\%) \\
\hline \multicolumn{3}{|l|}{ Umur (Tahun) } \\
\hline$<25$ tahun & 33 & 57.9 \\
\hline$\geq 25$ tahun & 24 & 42,1 \\
\hline \multicolumn{3}{|l|}{ Jenis Kelamin } \\
\hline Laki - Laki & 17 & 29,8 \\
\hline Perempuan & 40 & 70,2 \\
\hline \multicolumn{3}{|l|}{ Masa Kerja } \\
\hline$<5$ tahun & 48 & 84,2 \\
\hline$\geq 5$ tahun & 9 & 15,8 \\
\hline \multicolumn{3}{|l|}{ Status Perkawinan } \\
\hline Menikah & 22 & 38,6 \\
\hline Belum menikah & 35 & 61,4 \\
\hline
\end{tabular}

Analisis Univariat

Berdasarkan hasil penelitian dengan analisis univariat diketahui hasil pengukuran kelelahan perawat rawat inap shift pagi berdasarkan kuisoner di RS Herna Medan yang diberikan kepada perawat shift pagi, diketahui bahwa perawat yang sering merasakan kepala terasa berat sebanyak 11 orang $(57,9 \%)$ dan merasa lelah diseluruh badan sebanyak 9 orang $(47,4 \%)$.

Hasil pengukuran kelelahan perawat shift sore berdasarkan kuisoner di RS Herna Medanyang diberikan kepada perawat shift sore, diketahui bahwa perawat yang sering merasa ingin berbaring sebanyak 7 orang $(36,8 \%)$, merasa haus sebanyak 6 orang $(37,6 \%)$ dan merasa lelah diseluruh badan sebanyak 3 orang $(15,8 \%)$. Hasil pengukuran kelelahan perawat shift malam berdasarkan kuisoner di RS Herna Medan yang diberikan kepada perawat shift malam, diketahui bahwa perawat paling banyak merasakan mata terasa berat (ingin dipejamkan) sebanyak 9 orang $(47,4 \%)$, merasa pening dan pusing sebanyak 9 orang $(47,4 \%)$, sulit untuk berkonsentrasi sebanyak 8 orang $(42,1 \%)$, frekuensi menguap sebanyak 7 orang $(36,8 \%)$.

Dari hasil penelitian dapat dilihat bahwa tingkat kelelahan pada perawat Shift pagi(08.00 - $16.00 \mathrm{WIB})$ paling banyak dalam kategori kurang lelah yaitu 12 orang $(63,2 \%)$ dan dalam kategori 
lelah sebanyak 7 orang $(36,8 \%)$. Tingkat

kelelahan pada perawat Shift sore (16.00

- 23.00 wib) paling banyak dalam

kategori kurang lelah yaitu 12 orang $(63,2$

$\%)$, kategori lelah sebanyak 6 orang $(36,8$

$\%$ ) dan kategori sangat lelah sebanyak 1 orang $(5,3 \%)$.
Tingkat kelelahan pada perawat Shift malam (23.00 - 08.00 WIB) paling banyak berada dalam kategori kurang lelah 3 orang $(15,8 \%)$, kategori lelah sebanyak 14 orang $(73,7 \%)$ dan kategori sangat lelah sebanyak 2 orang (10,5\%).

Tabel 2 Distribusi Tingkat Kelelahan Perawat Rawat Inap

\begin{tabular}{lcc}
\hline Variabel & f & \% \\
\hline Shift Pagi & & \\
Kurang lelah & 12 & 63,2 \\
Lelah & 7 & 36,8 \\
\hline Shift Sore & & \\
\hline Kurang lelah & 12 & 63,2 \\
Lelah & 6 & 31,6 \\
Sangat Lelah & 1 & 5,3 \\
\hline Shift Malam & & \\
\hline Kurang lelah & 3 & 15,8 \\
Lelah & 14 & 73,7 \\
Sangat Lelah & 2 & 10,5 \\
\hline
\end{tabular}

\section{Analisis Bivariat}

Berdasarkan hasil penelitian dengan analisis bivariat diatas dapat dilihat bahwa tingkat kelelahan dalam kategori tidak lelah pada shift pagi, sore dan malam tidak ada (0\%). Tingkat kelelahan dalam kategori kurang lelah pada shift pagi sebanyak 12 orang $(63,6 \%)$, shift sore sebanyak $12(63,6 \%)$ dan shift malam 3 $(15,8 \%)$. Tingkat kelelahan dalam kategori lelah pada shift pagi sebanyak 7 orang ( $36,8 \%$ ), shift sore sebanyak 6 orang (31,6 $\%)$ dan shift malam sebanyak 14 orang $(73,3 \%)$ dan tingkat kekelahan dalam kategori sangat lelah pada shift pagi tidak ada $(0 \%)$, shift sore sebanyak 1 orang $(5,3 \%)$ dan shift malam sebanyak 2 orang ( $10,5 \%)$.

Pada hasil uji statistik dengan uji chi-square antara shift kerja dengan kelelahan dapat diketahui nilai pearson chi-square diperoleh p Value $=0.016$ dimana $\mathrm{p}<0,05$ yaitu $\mathrm{H}_{0}$ ditolak dan $\mathrm{Ha}$ diterima, artinya ada hubungan shift kerja dengan kelelahan pada perawat rawat inap di RS Herna Pekerja Indonesia. 
Tabel 3 Hubungan Shift Kerja dengan kelelahan pada perawat rawatinap

\section{Kelelahan}

\begin{tabular}{lccccccccc} 
Shift Kurang Lelah & \multicolumn{1}{c}{ Lelah } & \multicolumn{9}{c}{ Sangat Lelah Total } & \multicolumn{2}{c}{ Sig $(\boldsymbol{p})$} & & \\
& $\mathbf{f}$ & $\boldsymbol{\%}$ & $\mathbf{f}$ & $\boldsymbol{\%}$ & $\mathbf{f}$ & $\boldsymbol{\%}$ & $\mathbf{f}$ & $\boldsymbol{\%}$ & pvalue \\
\hline Pagi & 12 & 63,2 & 7 & 36,8 & 0 & 0 & 19 & 100 & \\
Sore & 12 & 63,2 & 6 & 31,6 & 1 & 5,3 & 19 & 100 & 0.016 \\
Malam & 3 & 15,8 & 14 & 73,7 & 2 & 10,5 & 19 & 100 & \\
\hline
\end{tabular}

PEMBAHASAN

Hubungan Shift Kerja dengan

Kelelahan pada Perawat Rawat Inap

Shift Pagi

Pada hasil uji statistik chi-square

dapat diketahui pada shift pagi terdapat tingkat kelelahan dalam kategori tidak lelah tidak ada, dalam kategori kurang lelah sebanyak 12 orang $(63,2 \%)$, dalam kategori lelah sebanyak 7 orang ( $36,8 \%)$ dan dalam kategori sangat lelah tidak ada. Perawat rawat inap shift pagi banyak terdapat perawat yang sering merasakan kepala terasa berat dan merasa lelah diseluruh badan disebabkan banyak melakukan aktivitas fisik seperti mendampingi dokter saat memeriksa keadaan pasien, melengkapi data pasien, mengantar pasien yang akan melakukan pemeriksaan laboratorium, fisiologi, radiologi dan mengantarkan pasien yang akan dioperasi. Tetapi pada perawat shift pagi tidak banyak yang mengeluh lelah karena perawat yang bekerja pada shift pagi setelah pulang kerja bisa menggunakan waktu istirahatnya untuk tidur dan bisa tidur dimalam hari.

Shift Sore
Pada hasil uji statistik chi-square dapat diketahui pada shift sore terdapat tingkat kelelahan dalam kategori tidak lelah tidak ada, dalam kategori kurang lelah sebanyak 12 orang $(63,2 \%)$, dalam kategori lelah sebanyak 6 orang $(31,6 \%)$ dan dalam kategori sangat lelah sebanyak 1 orang $(5,3 \%)$. Pada perawat rawat inap shift sore terdapat perawat sering merasa ingin berbaring, merasa haus dan merasa lelah diseluruh badan disebabkan karena pekerjaan perawat pada shift sore melanjutkan tugas pekerjaan perawat shift pagi yang belum selesai seperti mengurus berkas administrasi yang belum siap, mengobservasi pasien kembali, mengganti infuse pasien, menunggu dokter yang belum datang, memberi obat pasien, mengantar pasien yang akan melakukan pemeriksaan laboratorium, fisiologi, radiologi dan mengantarkan pasien yang akan dioperasi. Pada perawat shift siang ada beberapa perawat yang mengeluh lelah karena jumlah tenaga perawatnya lebih sedikit dan jam kerjanya sampai jam 23.00 WIB sehingga mereka mengantuk dan lelah. 
Shift Malam

Pada hasil uji statistik chi-square dapat diketahui pada shift malam terdapat tingkat kelelahan dalam kategori tidak lelah tidak ada, dalam kategori kurang lelah sebanyak 3 orang $(15,8 \%)$, dalam kategori lelah sebanyak 14 orang $(73,7 \%)$ dan dalam kategori sangat lelah sebanyak 2 orang $(10,5 \%)$. Pada perawat rawat inap shift malam terdapat perawat merasakan mata terasa berat (ingin dipejamkan), merasa pening atau pusing, frekuensi menguap dan sulit untuk berkonsentrasi disebabkan karena pekerjaan perawat melanjutkan pekerjaan perawat shift sore dan perawat shift malam banyak mengalami gangguan tidur, kurang istirahat sehingga menyebabkan cepat mengalami kelelahan apalagi yang sudah bekeluarga dan memiliki anak serta jam shift malam yang lebih panjang dibandingkan shift pagi dan shift sore.

Berdasarkan Hasil uji statistik chisquare dengan menggunakan program SPSS menunjukkan bahwa ada hubungan yang sangat signifikan antara shift kerja dengan kelelahan. Hal ini ditunjukkan dengan nilai signifikan $\mathrm{p}=0.016$ atau $\mathrm{p}<$ 0,05. Dari analisis ini dapat diketahui bahwa diantara shift pagi, sore dan malam yang memiliki tingkat kelelahan yang paling tinggi ditemukan pada shift malam karena jam kerjanya yang panjang mencapai 9 jam dalam satu shift serta waktu tidur yang kurang mengakibatkan perawat sering mengantuk dan ingin berbaring. Diketahui bahwa waktu tidur di siang hari tidak seefektif saat malam hari. Banyaknya aktivitas yang dilakukan oleh perawat juga dituntut untuk memberikan tindakan asuhan keperawatan yang baik untuk pasien serta selalu siaga dan tidak boleh lengah dalam mengawasi pasien. Perawat yang bekerja pada malam hari sangat mudah lelah karena waktu yang seharusnya digunakan untuk tidur dan istirahat, justru digunakan untuk bekerja dan hal ini sangat bertentangan dengan irama sirkadian tubuh.

Menurut Suma'mur terdapat lima kelompok sebab kelelahan yaitu keadaan monoton, beban dan lamanya pekerjaan baik fisik maupun mental, keadaan lingkungan seperti cuaca kerja, penerangan dan kebisingan, keadaan kejiwaan seperti tanggung jawab, kekhawatiran atau konflik serta penyakit, perasaan sakit dan keadaan gizi (Suma'mur, 1989).

Hal ini sesuai dengan pendapat nurmianto bahwa pekerja yang bekerja dimalam hari, dapat terkena beberap permasalahan kesehatan. Permasalahan kesehatan ini antara lain yaitu gangguan tidur, kelelahan, penyakit jantung, tekanan 
darah tinggi dan gangguan gastrointernasioal (Nurmianto, 2018). Selain itu, perawat shift malam juga sering mengalami gejala kelelahan merasa lelah sebelum bekerja yang dikarenakan perawat sudah banyak melakukan aktivitas pada saat siang hari diluar pekerjaan mereka, seperti mengurus anak dan kebutuhan rumah tangga. Hal ini dikarenakan sebagian perawat sudah berkeluarga. Menurut Fatona, seseorang yang sudah menikah akan memiliki tugas seperti mulai hidup berkeluarga, memelihara anak, mengatur rumah tangga, dan memulai dalam pekerjaan. Sehingga seseorang yang sudah menikah akan mengalami kelelahan kerja akibat kerja dan sesampainya dirumah harus mengurus kebutuhan keluarga yang mana waktu tersebut harus digunakan untuk istirahat (Lusi, 2015).

Penelitian yang sama oleh wilda susanti yang berjudul hubungan shift kerja dengan kelelahan pada perawat rawat inap di RSU Haji Medan yaitu menyatakan bahwa ada hubungan yang bermakna antara shift kerja dengan Kelelahan dengan $p=0,002<\alpha=0,05 .(18)$ Hasil penelitian yang dilakukan Pratiwi (2016) didapatkan nilai $\mathrm{p}<0,000$ yang menyatakan terdapat hubungan shift kerja dengan kelelahan kerja pada pekerja bagian daily check di PT.Kereta Api Daerah Operasi VI
Yogyakarta DIPO Kereta Solo Balapan. Saran untuk PT.Kereta Api Daerah Operasi VI Yogyakarta DIPO Kereta Solo Balapan adalah memperluas rest area yang sudah ada sehingga pekerja dapat tidur untuk mengurangi kelelahan dan untuk meningkatkan motivasi kerja bagi para pekerja (Pratiwi, 2016)

Penelitian ini juga didukung oleh penelitian yang berjudul perbedaan tingkat kelelahan antara shift pagi, sore dan malam pada perawat rawat inap di RS PKU Aisyiyah Boyolali. Tingkat kelelahan berdasarkan shift perawat rawat inap di RS PKU Aisyiyah Boyolali menunjukan bahwa tingkat kelelahan yang lebih besar pada shift malam $(31,82 \%)$, tingkat kelelahan sedang berada pada shift pagi $(22,69 \%)$ dan tingkat kelelahan paling rendah pada shift siang $(20,13 \%)$ dan menunjukkan terdapat perbedaan tingkat kelelahan pada shift pagi, sore dan malam pada perawat dengan nilai $\mathrm{p}=0,038<\alpha=$ 0,05 (Lusi, 2015).

Penelitian yang dilakukan oleh pramitasari tentang pengaruh masa kerja dan shift kerja terhadap kelelahan kerja pada perawat rawat inap di RS PKU Muhammdiyah Surakarta yaitu menyatakan terdapat pengaruh yang siginifikan antara shift kerja dan kelelahan 
kerja $\mathrm{p}=0,000<\alpha=0,05$ (Pramitasari, 2016).

Penelitian yang dilakukan oleh Sefriadinata Affandi (2013) dengan judul Hubungan Beban Kerja dengan Kinerja $\begin{array}{lll}\text { Perawat di } & \text { RSUD }\end{array}$ HusadaPurworejomenunjukkan bahwa terdapat hubungan yang signifikan antara beban kerja dengan kinerja perawat di RSUD Saras Husada Purworejo, dengan signifikan $\mathrm{p}=0,00$ dan koefisien korelasi $\mathrm{r}$ $=-0.537$ (Sefridinata, 2013).

Hasil penelitian yang dilakukan Irianti (2017) ini menunjukkan bahwa shift kerja signifikan mempengaruhi tingkat kelelahan dan performansi pengendali kereta api. Kelelahan signifikan terjadi pada tingkat kantuk (sleepiness), ketidaknyamanan fisik (physical discomfort) dan penurunan motivasi (lack of motivation) sedangkan pada performansi pada parameter mean 1/RT, fastest $10 \%$ 1/RT dan slowest 10\% 1/RT ( $\mathrm{P}<0,10)$. Tingkat kelelahan tertinggi dan performansi terburuk terjadi setelah shift malam. Tingkat kelelahan setelah shift malam meningkat sekitar 37\%-162\% sedangkan performansi menurun sekitar 3\%-11\%. Meskipun tingkat kelelahan antar shift berbeda secara signifikan, namun nilai yang dihasilkan sangat kecil, hal ini menunjukkan bahwa kelelahan yang dirasa sangat rendah. Berdasarkan hasil penelitian ini, tindakan perbaikan terhadap sistem shift kerja tidak terlalu diperlukan, namun jam kerja masing-masing shift masih perlu mendapat perhatian (Irianti, 2017).

\section{KESIMPULAN}

Berdasarkan hasil penelitian yang telah dilakukan pada perawat di instalasi rawat inap di RS Herna Medan tahun 2018, dapat disimpulkan terdapat hubungan shift kerja dengan kelelahan kerja pada perawat rawat inap di RS Herna Medan, tingkat kelelahan yang paling tinggi terdapat pada perawat shift malam yang dimana terdapat 14 orang yang merasakan lelah dan 2 orangmerasakan sangat lelah dan tingkat kelelahan terendah terdapat pada shift pagi karena perawat yang bekerja pada shift pagi setelah pulang kerja bisa menggunakan waktu istirahatnya untuk tidur dan bisa tidur dimalam hari.

\section{SARAN}

Kepada perawat agar memanfaatkan waktu istirahat sebaik mungkin, dan bisa mengatur sendiri waktu istirahat dan waktu tidur untuk meminimalisir terjadinya kelelahan kerja. Disarankan juga kepada perawat shift malam agar mampu beradaptasi dimalam hari dengan memanfaatkan waktu senggang untuk istirahat dan untuk mengurangi kelelahan perawat dapat melakukan refreshing pada 
saat libur atu berolahraga secara teratur dan juga relaksasi.

\section{DAFTAR PUSTAKA}

Adisasmito W. Sistem Manajemen Lingkungan Rumah Sakit. Jakarta: Raja Grafindo Persaada; 2007.

Budiono S. Konsep Dasar Keperawatan. Jakarta: Bumi Medika; 2015.

Fajar Pratiwi C. Hubungan Shift Kerja Dengan Kelelahan Kerja Pada Pekerja Bagian Daily Check di PT. Kereta Api Daerah Operasi VI Yogyakarta Dipo Kereta Api Solo Balapan. 2016;

Febrian R. Nursepreneurship; Gagasan \& Praktik Kewirausahaan dalam Keperawatan. Yogyakarta: Trans Medika; 2015.

Irianti L. Pengaruh Shift Kerja Terhadap Kelelahan dan Performansi Pengendali Kereta Api Indonesia. 2017;6(2):79-92.

Kementerian Kesehatan RI. Undangundang Republik Indonesia Nomor 38 Tahun 2014 tentang Keperawatan. 2014;Kemenkes RI. Available from: https://www.kemenkopmk.go.id/sit es/default/files/produkhukum/UU Nomor 38 Tahun 2014.pdf.

Kepmennakertas. Keputusan Menteri Tenaga Kerja dan Transmigrasi No.Kep.233/MEN/VI/2004. 2003;

Laporan penelitian Persatuan Perawat Nasional Indonesia ( PPNI) tahun 2016. 2016;Nurmianto E. Ergonomi Konsep Dasar dan Aplikasinya. Surabaya: Guna Widya; 2018.

Lusi F. Perbedaan Tingkat Kelelahan Antara Shift Pagi, Sore Dan Malam Pada Perawat Rawat Inap Di RS PKU Aisyiyah Boyolali. 2015; Kementerian Kesehatan Indonesia.
Undang-undang Republik Indonesia Nomor 13 Tahun 2003. 2013;1(1):1-84.

Margono. Metodologi penelitian Pendidikan. Jakarta: Rineka Cipta; 2013.

Notoadmodjo S. Metodologi Penelitian Kesehatan. Jakarta: Rineka Cipta; 2005.

Pramitasari RM. Pengaruh Masa Kerja dan Shift Kerja Terhadap Kelelahan Kerja pada Perawat Inap di Rumah Sakit PKU Muhammadiyah Surakarta. 2016;

RS Herna . Profil RS Herna Medan tahun 2016. 2016.

Sefridinata T. Hubungan Beban Kerja dengan Kinerja Perawat di RSUD Saras Husada Purworejo. 2013;

Sucipto DC. Kesehatan dan Kesehatan Kerja. Yogyakarta: Gosyen Publishing; 2014.

Sugeng Budiono AM, RMS J, Pusparini A. Bunga Rampai Hiperkes dan KK. Semarang: Badan Penerbit Universitas Diponegoro; 2003.

Suma'mur P.K. Ergonomi untuk produktivitas Kerja. Jakarta: Haji masagung; 1989.

Susanti W. Hubungan Shift Kerja Dengan Kelelahan Pada Perawat Rawat Inap Di Rsu Haji Medan Tahun 2017. 2017;

Tarwaka. Ergonomi Untuk Keselamatan, Kesehatan Kerja dan Produktivitas. Surakarta: UBIBA Press; 2004. 